\title{
Enhanced Efficacy and Bioavailability of Skin-Care Ingredients Using Liposome and Nano-liposome Technology
}

\author{
Dokhani A, Amini J, Gortzi O, Danaei M, Mozafari MR* and Maherani B \\ Department of Food Technology, University of Applied Sciences of Thessaly, Greece \\ Australasian Nano-science and Nano-technology Initiative, Monash University LPO, Australia \\ Research Laboratories in Sciences Applied to Food, INRS-Institute Armand-Frappier, Canada
}

Submission: September 15, 2017; Published: September 22, 2017

*Corresponding author: Mozafari MR, RAustralasian Nanoscience and Nanotechnology Initiative, Monash University LPO, Australia, Email: dr.m.r.mozafari@gmail.com

\begin{abstract}
Skin is considered to be the largest and fastest-growing organ in Human body and plays an important role in providing protection from pathogens and environmental factors. Due to its large surface area, skin is susceptible to a variety of conditions including acne, dermatitis, eczema, psoriasis, rashes, cellulitis and rosacea. External factors such as skin care products, exogenous chemicals, and the weather can influence the skin from outside while the food and medicines consumed by individuals can lead to the development of skin disorders from inside the body. Although there are numerous products on the market for skin conditions and skin health and beauty, active research and development for potent remedies are still ongoing. An efficient strategy to enhance the efficacy of skin care products and improve their bioavailability and provide longlasting effect is employment of encapsulation systems such as liposomes and nano liposomes. Here a summary of methods to enhance the efficacy and bioavailability of skin care ingredients is presented.
\end{abstract}

Keywords: Bioavailability; Encapsulation; Liposome's; Nano-liposome's; Psoriasis; Topical

\section{Introduction}

In a topical sense, the word "bioavailability" can be defined as the extent to which a pharmaceutical active compound (e.g. in the form of cream, lotion, etc.) or a nourishing factor or a cosmetic product reaches its site of action or can enter a biological fluid such as blood. Bioavailability of a pharmaceutical compound is largely determined by the properties of the dosage form, which partially depend on its design and formulation, rather than by the drug's physicochemical properties, which determine drug's absorption potential [1].

It has been postulated that nanotechnology can improve the bioavailability of skin care products including cosmetic formulations [2]. Nanotechnology refers to design, characterization, manufacture, assembly and application of structures, devices and systems by controlling shape, functionality and scale at nanometer size range. Within a short period of time since its emergence, nano-technology has found applications in different fields of medicine (referred to as nanomedicine and nano-therapy), biotechnology, pharmaceutics, agriculture, food, nutrition, and cosmetics [3-6]. Currently, nanotechnology is an integral part of pharmaceutics and drug delivery systems. In pharmaceutical sciences and cosmetics size is an important parameter since it influences the drugs bioavailability, toxicity, shelf life and efficacy. Nano size can significantly enhance drug performance. It provides intelligent systems, devices and materials for efficient pharmaceutical applications. Nanotechnology-based drug delivery systems can improve bio-distribution and bioavailability of therapeutic agents and active compounds. Liposome and nano-liposome technology have the potential properties of a controlled release system to achieve effective drug delivery whilst reducing problems related to targeted delivery, bio-distribution and bioavailability of drugs, especially when administering potentially toxic and cytotoxic agents $[7,8]$. In this review advantages of liposome's and nanoliposomes for the encapsulation and delivery of skin-care products are summarized.

\section{Transdermal Delivery of Bioactive Compounds}

Because of the accessibility and large surface area of the skin, it has long been considered as a promising route for the administration of bioactive agents, where dermal, regional, or systemic effects are desired. The advantages of the topical 
route of drug administration include: avoidance of the risks and inconvenience of parenteral treatment; avoidance of the variable absorption and metabolism associated with oral treatment; continuity of drug administration, permitting use of pharmacologically active agents with short biological halflives and potential reduction of gastrointestinal irritation in systemic administration [9]. However, the impermeability of skin is a well-known phenomenon serving as a barrier to access of pathogens and toxic chemicals, and exit of physiological fluids. This impermeability is the result of normal physiologic changes in a developing skin, which also results in lesser bioavailability of active compounds. It is already well known that bioavailability of therapeutic compounds taken topically are always lesser than those taken orally or intravenously. Bioavailability of topical dosage forms that are not intended for absorption has proven to be quite difficult, discouraging and extremely challenging.

In the past decades, there has been an increasing research interest in the development of topical delivery of therapeutic agents because of a number of advantages offered by this route. Topical drug delivery refers to the application of active compounds to the skin for localized effect and in transdermal drug delivery skin is used as a potential route for the local or systemic action of drugs. Transdermal drug delivery systems offer a number of advantages such as longer duration of action, flexibility in dosing, reduced side effects, uniform plasma levels, and high patient compliance. Transdermal delivery of therapeutic compounds, however, may possess some drawbacks including possibility of local irritation effect, erythema, itching, and most importantly the low permeability of drugs in the stratum corneum. Many drug delivery technologies and carrier systems have been investigated to overcome this barrier among which liposomes and nano-liposome are considered to be the most promising techniques for drug delivery through the skin [10].

\section{Liposomes and Nano-Liposomes}

Liposome refers to a terminology originated from two Greek words: 'Lipos' that means fat and 'Soma' which means body. This vesicular bilayer system was first described by British hematologists Dr. Alec D. Bangham in 1961 (published in 1964), at the Babraham Institute, in Cambridge [11]. Liposomes are used as a drug delivery carrier in immunology applications, vaccine adjuvant, eye disorders, brain targeting, and infectious disease and in cancer therapy to name but a few. They are also used in topical delivery of bioactive agents and cosmetic products since they can improve the drug deposition within the skin at the site of action where the goal is to reduce systemic absorption and thus minimize side effects, increase patient compliance and enhance bioavailability. Figure 1 depicts a liposomal antiaging and antioxidant cream developed by our group. This topical cream is manufactured employing "Sustained Release Technology" and provides long-lasting effect, penetrates into the skin and helps reduce the visible signs of ageing. Liposome's are used in this product to encapsulate, protect and deliver the active ingredients to the right place where they are most needed in the skin and provide a long-lasting effect. This cream effectively reduces dehydration of the skin and restores its normal balance, shallow expression lines and wrinkles. Complex of antioxidants are used in the product to protect the skin against free radicals and against antioxidant stress. The liposomal component is manufactured using our environment-friendly, green technology, proprietary procedure known as "Mozafari Method" [12].

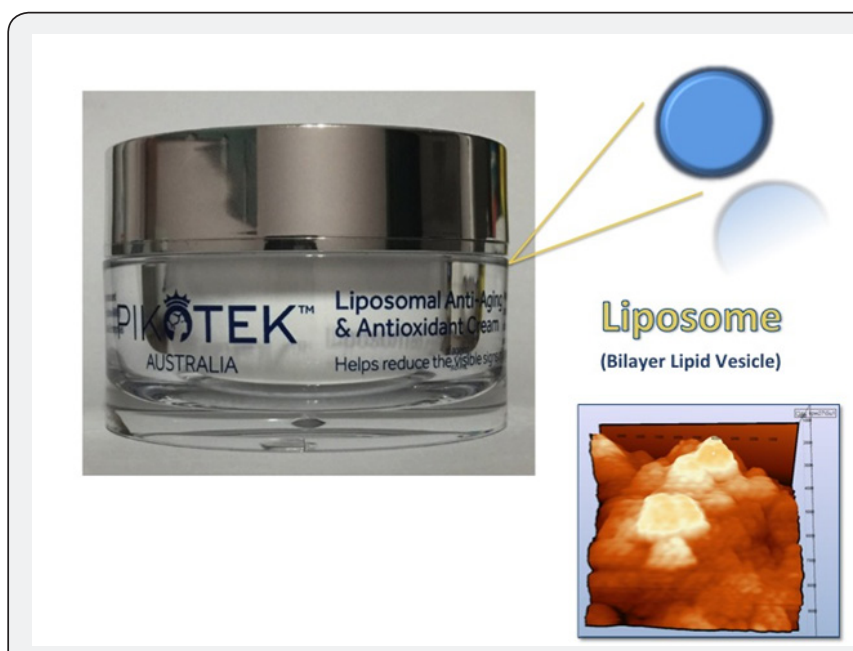

Figure 1: Liposomal antioxidant and anti-aging cream prepared by Mozafari Method. Inset depicts atomic force microscopy (AFM) image of the liposomes inside the cream.

Liposome's can range in size from ca. $200 \mathrm{~nm}$ up to several micrometers. Nanoliposomes are nano-metric version of liposomes while vesicular phospholipids gels and the recently introduced "tocosomes" are derivatives of these colloidal drug delivery systems [13-16]. Applications of liposome and nano-liposome technology in skin treatment are based on the similarity of the bilayer structure of liposome / nano-liposome to that of the natural bio-membranes. Therefore, depending on the lipid composition of liposome and nano-liposome, they can alter cell membrane fluidity and deliver active ingredients to the site of action. Different forms of liposome preparations such as solution, creams, gels and ointments can deliver compounds across the stratum corneum [17].

Liposome's composed of a natural marine lipid containing polyunsaturated fatty acids (PUFA) were recently introduced as Marionosomes ${ }^{\circledR}$ for the prevention and treatment of skin diseases [18]. These lipids exhibit anti-inflammatory properties in vitro and have variety of benefits regarding inflammatory skin disorders and metabolized by skin epidermal enzymes into antiinflammatory and anti-proliferative metabolites. These types of liposomes provide valuable raw material for their generation, humidifying and softening the skin [17]. Nutracosmetics are an emerging class of health and beauty products that combine the herbs and liposome's / nanoliposomes to maintain and enhance human beauty because of their beneficial properties, such as sunscreen, anti-aging, moisturizing, antioxidant, anti-cellulite, and antimicrobial effects [17]. 


\section{Conclusion}

Due to their unique properties, including low or complete lack of cytotoxicity, good biocompatibility and biodegradability, liposome's and nanoliposomes possess wide applications in different fields including gene and drug delivery, food and nutrition industries and cosmetics. In topical applications, liposomes /nano liposomes can improve bioavailability and increase efficacy of skin care products significantly. As a result of these attributes, they are considered safe by international regulatory agencies such as FDA. Consequently, we are witnessing increasing number of cosmetic and skin care products containing liposome and nano-liposome technology on the market.

\section{References}

1. Bhadoriya SS, Mangal A, Madoriya N, Dixit P (2011) Bioavailability and bioactivity enhancement of herbal drugs by "Nanotechnology": a review. JCPR 8(1): 1-7.

2. https://www.linkedin.com/pulse/cosmetic

3. Mozafari MR (2006) Nan carrier technologies: frontiers of nanotherapy In: Mozafari MR (Ed.), Springer, Dordrecht, The Netherlands, p. 225.

4. Mozafari MR (2007) Nanomaterials and nanosystems for biomedical applications. In: Mozafari MR (Ed.), Springer Science \& Business Media, Netherlands.

5. Mozafari MR, Johnson C, Hatziantoniou S, Demetzos C (2008) Nanoliposomes and their applications in food nanotechnology. J Liposome Res 18(4): 309-327.

6. Nohynek GJ, Dufour EK, Roberts MS (2008) Nanotechnology, cosmetics and the skin: is there a health risk? Skin Pharmacol Physiol 21(3): 136149.

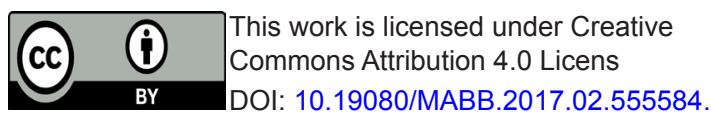

7. Leeuw DJ, Vijlder DHC, Bjerring Neumann PHAM (2009) Liposomes in dermatology today. J Eur Acad Dermatol Venereol 23(5): 505-516.

8. Sharma A, Sharma US (1997) Liposomes in drug delivery: progress and limitations. International Journal of Pharmaceutics 154(2): 123-140.

9. Deckner GE, Lombardo BS (1999) Patent and Trademark Office. US Patent No. 5,874,095. Washington DC, USA.

10. Shilakari G, Singh D, Asthana A (2013) Novel vesicular carriers for topical drug delivery and their applications. Int J Pharm Sci Rev Res 21(1): 77-86.

11. Bangham AD, Horne RW (1964) Negative staining of phospholipids and their structural modification by surface-active agents as observed in the electron microscope. Journal of Molecular Biology 8(5): 660-668.

12. Mozafari MR (2010) Method for the preparation of micro-and nanosized carrier systems for the encapsulation of bioactive substances. Patent Application No. 12/790,991, USA.

13. Mozafari MR (2005) Liposomes: an overview of manufacturing techniques. Cell Mol Biol Lett 10(4): 711-719.

14. Brandl M (2010) Vesicular phospholipid gels. Methods Mol Biol 605: 205-212.

15. Fathi M, Mozafari MR, Mohebbi M (2012) Nano encapsulation of food ingredients using lipid based delivery systems. Trends in Food Science \& Technology 23(1): 13-27.

16. Mozafari MR, Javanmarda R, Raji M (2017) Tocosome: novel drug delivery system containing phospholipids and tocopheryl phosphates. Int J Pharm 528 (1-2): 381-382.

17. Maherani B, Tehrany AE, Mozafari MR, Gaiani C, Linder M, et al. (2011) Liposomes: a review of manufacturing techniques and targeting strategies. Current Nanoscience 7(3): 436-452.

18. Moussaoui N, Cansell M, Denizot A (2002) Marinosomes ${ }^{\circledR}$, marine lipid based liposomes: Physical characterization and potential application in cosmetics. Int J Pharm 242(1-2): 361-365.

\section{Your next submission with Juniper Publishers will reach you the below assets}

- Quality Editorial service

- Swift Peer Review

- Reprints availability

- E-prints Service

- Manuscript Podcast for convenient understanding

- Global attainment for your research

- Manuscript accessibility in different formats

( Pdf, E-pub, Full Text, Audio)

- Unceasing customer service

Track the below URL for one-step submission https://juniperpublishers.com/online-submission.php 